\title{
Avaliação da influência da estação de tratamento de efluente de Catanduva (SP) na qualidade da água do rio São Domingos
}

\author{
Evaluation of influence of the Catanduva (SP) Wastewater Treatment \\ Plant (WWTP) in São Domingos river water quality
}

\author{
Wagner Cleyton Fonseca'* ${ }^{1 *}$, Carlos Eduardo Junqueira de Azevedo Tibiriçá1
}

\section{RESUMO}

O efluente sanitário bruto é um dos responsáveis pela poluição de rios urbanos, e a instalação de estações de tratamento de efluentes (ETE) exige uma avaliação comparativa do comportamento desses rios antes e depois da ETE. Este trabalho objetivou avaliar a qualidade da água do rio São Domingos (RSD) após o início da operação da ETE Catanduva (SP), cujas eficiências médias de remoção foram: demanda bioquímica de oxigênio (93,71\%), nitrogênio amoniacal (73,12\%), fósforo total (25,70\%), turbidez (85,16\%) e ST (31,75\%). Foram utilizados 768 dados coletados pela Companhia Ambiental do Estado de São Paulo a montante e a jusante de Catanduva (SP). Obras de dragagem realizadas durante o período avaliado foram responsáveis por um significativo decréscimo temporário na qualidade da água do RSD em Catanduva. Após dois anos do início da operação da ETE, houve significativa melhoria na qualidade do RSD, com redução das concentrações médias de DBO (de 20,97 para 5,73 mg..'1), nitrogênio amoniacal (de 3,84 para 0,99 mg..-1) e Escherichia coli (de $10^{5}$ para $10^{4}$ UFC.100 mL-1) e aumento da concentração de oxigênio dissolvido (de 0,90 para 3,12 mg. $\mathrm{L}^{-1}$ ). A análise de componentes principais indicou que a qualidade do rio a jusante de Catanduva está-se aproximando da boa qualidade verificada a montante da cidade. Esses dados sugerem que o RSD pode futuramente ser classificado como Classe 3 (Resolução do Conselho Nacional do Meio Ambiente - CONAMA no 357/05) e até ser utilizado para abastecimento humano, reduzindo a elevada demanda de água subterrânea na região.

Palavras-chave: rios urbanos; efluente doméstico; poluição; impacto ambiental; análise de componentes principais.

\begin{abstract}
Non-treated wastewater is responsible for the pollution of urban rivers, and it is mandatory to evaluate the behavior of these rivers before and after the construction of a Wastewater Treatment Plant (WWTP). The aim of this study was to evaluate the water quality of São Domingos River (SDR) after the start of the Catanduva/SP WWTP operation, whose average removal efficiencies were: biochemical oxygen demand (BOD; 93.71\%), ammonia nitrogen (73.12\%), total phosphorus (25.70\%), turbidity (85.16\%), and total solids (31.75\%). We used 768 data collected upstream and downstream of the city of Catanduva/SP, previously analyzed by CETESB (state environmental agency). Dredging works carried out during the evaluated period were responsible for a significant temporary worsening in the water quality of the SDR in Catanduva. Two years after the beginning of the Catanduva WWTP, there was a significant improvement in SDR water quality, with a reduction in the average concentrations of BOD (20.97 to 5.73 mg. $\mathrm{L}^{-1}$ ), ammonia nitrogen (3.84 for $\left.0.99 \mathrm{mg} \mathrm{L}^{-1}\right)$, and Escherichia coli $\left(10^{5}\right.$ to $10^{4}$ CFU.100 $\left.\mathrm{mL}^{-1}\right)$ were reduced; and DO concentration ( 0.90 to 3.12 mg. $\mathrm{L}^{-1}$ ) increased. The Principal Component Analysis (PCA) indicated that the water quality of the river downstream of Catanduva is approaching the same quality verified upstream of the city. These data suggest that SDR may be considered a Class 3 river (Resolution CONAMA 357/05) in the future and may even be used for human supply, reducing the high demand for groundwater in the region.
\end{abstract}

Keywords: urban rivers; domestic effluents; pollution; environmental impacts; principal component analysis.

\section{INTRODUÇÃO}

Uma das principais causas da depreciação da qualidade da água em rios urbanos é a contaminação com esgoto doméstico, o que pode resultar na proliferação de micro e macroalgas e na redução na biodiversidade da fauna local, além de afetar

a saúde pública com a transmissão de doenças de veiculação hídrica (AISSAGROUZ; GARNIER; BILLEN, 2018). A solução encontrada é a instalação de rede coletora que conduza os efluentes para estações de tratamento de efluente (ETE) públicas, em substituição aos sistemas de tratamento individuais ou à total

口-

'Universidade do Vale do Itajaí - Itajaí, SC, Brasil.

*Autor correspondente: wagnerfonseca@univali.br

Conflitos de interesse: os autores declaram não haver conflito de interesses.

Financiamento: nenhum.

Recebido: 09/10/2018 - Aceito: 30/11/2019 - Reg. ABES: 20180157 
ausência de tratamento (BARILE, 2018; GARNIER et al., 2018). Contudo, são raras as publicações científicas que demonstrem a relevância da implantação de ETE para a melhoria da qualidade da água em rios urbanos.

As ETE são realidade há mais de 100 anos na maioria das cidades de países desenvolvidos, porém em países em desenvolvimento a existência de sistemas de coleta e tratamento de esgoto ainda é restrita a algumas regiões. Esse é o caso do Brasil, onde o índice de atendimento de coleta de esgoto é inferior a 10\% nos estados do Piauí, Rondônia e Pará, enquanto no Paraná e São Paulo esse índice é superior a 70\% (BRASIL, 2017). O estado de São Paulo possui índice de coleta de efluente sanitário de $79,61 \%$ e de tratamento de $77,17 \%$ do efluente coletado (BRASIL, 2017). Entretanto, no ano de 2015 ainda havia municípios paulistas populosos que lançavam efluente bruto, sem tratamento, em rios. Um exemplo é a cidade de Catanduva (SP), que lançava o efluente sanitário de 113 mil habitantes, sem tratamento, no rio São Domingos (RSD) até meados de 2015, causando significativas alterações na qualidade da água desse rio.

O monitoramento realizado pela Companhia Ambiental do Estado de São Paulo (CETESB) e outros trabalhos científicos demonstraram a degradação da qualidade do RSD pela zona urbana de Catanduva. Entre 2000 e 2010, a média das concentrações de oxigênio dissolvido (OD) a jusante da cidade foi de $1,2 \mathrm{mg} / \mathrm{L}$, enquanto a média de demanda bioquímica de oxigênio (DBO) foi de $14 \mathrm{mg} / \mathrm{L}$ (CETESB, 2011b). Os dados fornecidos pela Superintendência de Água e Esgoto de Catanduva (SAEC) também apontaram a poluição do RSD entre 2011 e 2012 com concentrações de OD variando de 0,20 a 2,88 mg/L e concentrações de DBO de 10 a $61 \mathrm{mg} / \mathrm{L}$ (TAMBELLINI, 2012). Diante desse cenário, restou evidente a poluição do RSD causada pela falta de tratamento do efluente sanitário gerado pela zona urbana de Catanduva.

A ETE de Catanduva iniciou sua operação em junho de 2015, entretanto não há estudos que relatem a situação do RSD desde a sua operação. O presente trabalho tem como objetivos analisar se a ETE de Catanduva alterou o cenário de poluição do RSD e se há tendência de ampliação dos usos da água desse rio, visto que as vazões outorgadas de captação de água subterrânea na cidade de Catanduva já ultrapassaram as reservas exploráveis em 497,19\%, excluídas as do Aquífero Guarani (CBH-TG, 2018), o que indica que pode haver inviabilização do abastecimento em médio e longo prazo.

\section{Caracterização da área de estudo}

O estudo foi desenvolvido na sub-bacia do RSD situada na porção noroeste do estado de São Paulo, que pertence à Unidade de Gerenciamento de Recursos Hídricos (UGRHI) no 15, denominada de Turvo/Grande (Figura 1). A sub-bacia possui $855 \mathrm{~km}^{2}$, equivalendo a 5\% da UGRHI Turvo/Grande, sendo o RSD o principal curso d'água, enquadrado como Classe 4 (Resolução do Conselho Nacional do Meio Ambiente CONAMA n ${ }^{\circ}$ 357/05) (BRASIL, 2005) em toda a sua extensão (SÃO PAULO, 1977).

A bacia hidrográfica do RSD abrange os municípios paulistas de Ariranha, Catanduva, Catiguá, Cedral, Pindorama, Santa Adélia, Tabapuã e Uchoa. Nesses municípios a ocupação predominante do solo é para o cultivo de cana-de-açúcar,

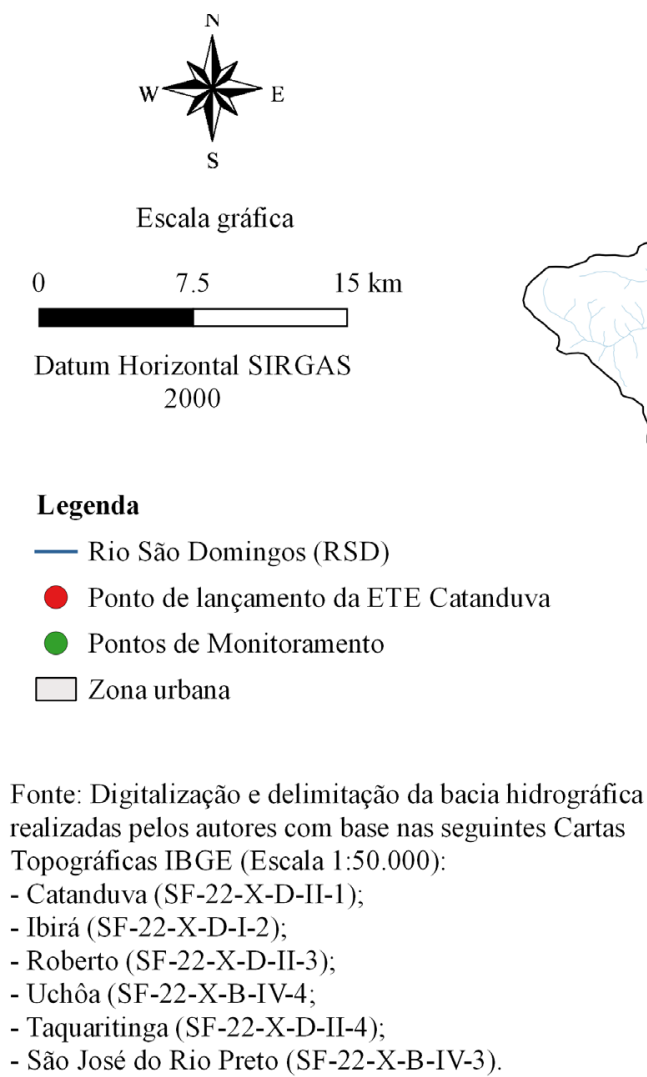

Fonte: Digitalização e delimitação da bacia hidrográfica realizadas pelos autores com base nas seguintes Cartas Topográficas IBGE (Escala 1:50.000):

- Catanduva (SF-22-X-D-II-1);

- Ibirá (SF-22-X-D-I-2);

- Roberto (SF-22-X-D-II-3);

- Uchôa (SF-22-X-B-IV-4;

- Taquaritinga (SF-22-X-D-II-4);

- São José do Rio Preto (SF-22-X-B-IV-3).

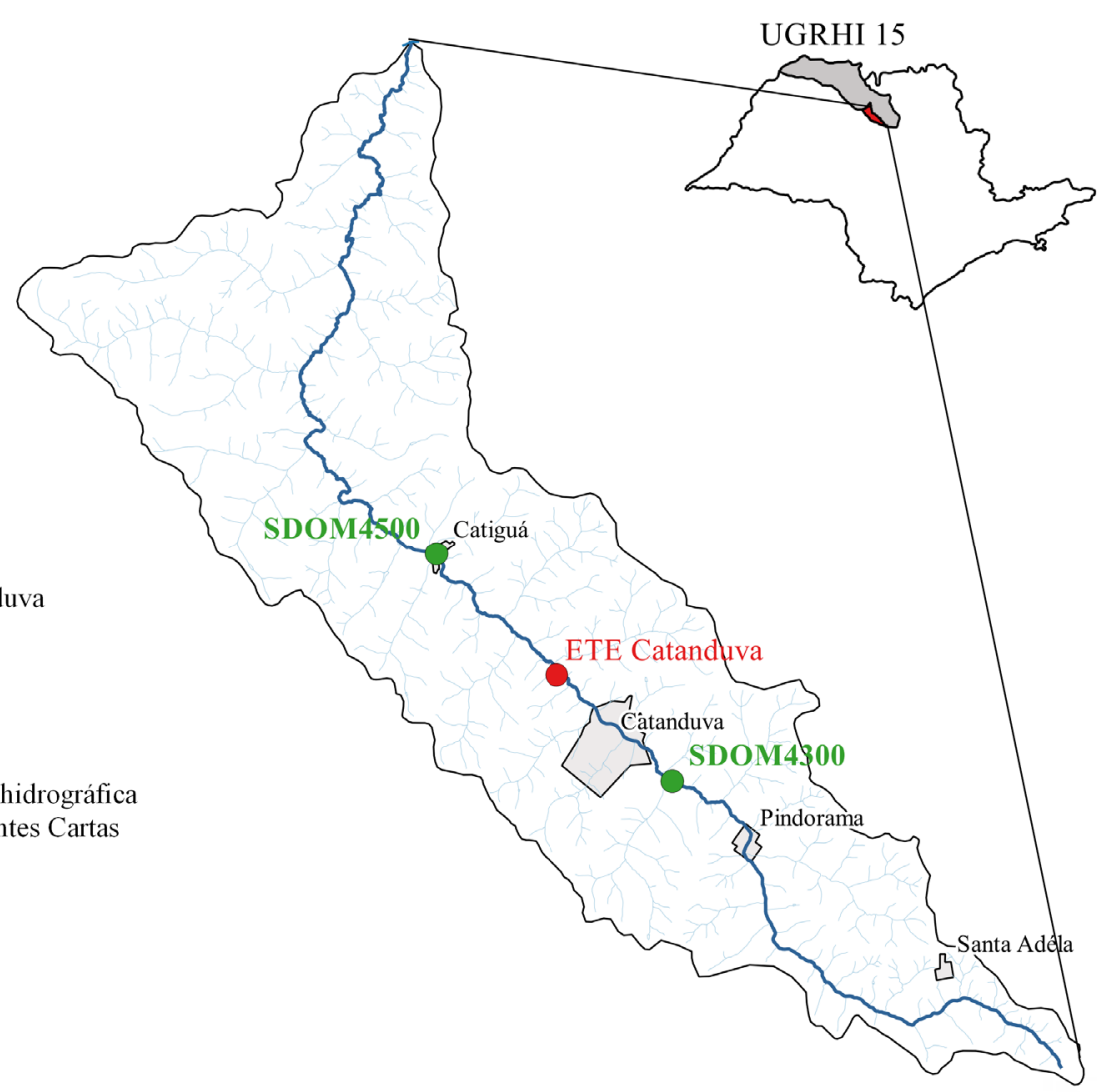

Fonte: Elaborada pelos autores (2018)

Figura 1 - Bacia hidrográfica do rio São Domingos. 
criação de bovinos e culturas perenes, tais como: laranja, café, banana, uva e seringueira (CBH-TG, 2018). O RSD nasce no município de Santa Adélia e atravessa a zona urbana de Pindorama, Catanduva e Catiguá (Figura 1), recebendo o efluente desses quatro municípios. Santa Adélia e Pindorama possuem quase $100 \%$ de coleta e tratamento de efluentes (CETESB, 2016), e as ETE desses dois municípios iniciaram suas operações em 2003 e 2008, ao passo que a cidade de Catanduva passou a operar sua ETE apenas no ano de 2015 (Tabela 1).

O município de Catanduva tem o maior potencial de poluição do RSD por ser a cidade mais populosa da sub-bacia, e até o ano de 2015 lançava todo o efluente doméstico sem tratamento nesse rio. No que tange ao efluente industrial, as usinas de açúcar e álcool não lançam efluente no RSD por utilizá-los na fertirrigação, porém uma empresa de laticínios e outra de café solúvel lançavam seus efluentes tratados no RSD em Catanduva (TAMBELINI, 2012). Os efluentes sanitário e dessas duas indústrias passaram a ser enviados à ETE de Catanduva.

A ETE de Catanduva iniciou sua operação em julho de 2015 e recebe o efluente gerado por toda a zona urbana, que passa pelas seguintes etapas na estação:

- gradeamento grosseiro;

- gradeamento fino;

- caixa de areia;

- lagoa aerada;

- lagoa de sedimentação;

- escada hidráulica.

O efluente tratado é lançado no RSD a jusante da zona urbana de Catanduva (Coordenadas UTM E 707.679 / S 7.664.542), a 9 km do ponto de monitoramento da CETESB denominado de SDOM4500.

\section{METODOLOGIA}

Os dados de qualidade do efluente bruto e tratado da ETE de Catanduva foram fornecidos pela SAEC, abrangendo sete coletas mensais entre novembro de 2016 e maio de 2017 (SAEC, 2017). O efluente bruto foi coletado antes do gradeamento fino, e o efluente tratado após a escada hidráulica. A vazão afluente e efluente à ETE incluiu medições diárias, totalizando 212 dados.

A influência da ETE de Catanduva foi avaliada por meio de dados de qualidade da água do RSD obtidos dos "Relatórios de Águas Interiores" elaborados pela CETESB (2011b, 2012; 2013; 2014; 2015; 2016; 2017; 2018), e foram considerados os dados de duas estações de monitoramento: SDOM4300 (a montante da cidade de Catanduva) e SDOM4500 (a jusante da cidade de Catanduva e do ponto de lançamento da ETE) (Figura 1). No presente estudo foram considerados os dados no intervalo de oito anos (2010 a 2017), visto que o monitoramento

Tabela 1 - Municípios que lançam efluente doméstico no rio São Domingos.

\begin{tabular}{l|c|c|c|c} 
& $\begin{array}{c}\text { Santa } \\
\text { Adélia }\end{array}$ & Pindorama & Catanduva & Catiguá \\
\hline População em 20171 & 15.331 & 16.656 & 120.691 & 7.700 \\
\hline Coleta de esgoto (\%) & 99 & 98 & 100 & 100 \\
\hline Tratamento de esgoto (\%) & 100 & 100 & 99 & 100 \\
\hline Início da operação da ETE & 2003 & 2008 & 2015 & 2010 \\
\hline Carga poluidora (kg DBO.dia'1)2 & 54 & 84 & 495 & 284 \\
\hline
\end{tabular}

ETE: estação de tratamento de efluente; DBO: demanda bioquímica de oxigênio. Fonte: 'IBGE (2018); ${ }^{2}$ Cetesb (2018) da estação SDOM4300 se iniciou apenas em 2010. Considerando que as ETE de Santa Adélia e Pindorama estavam em operação antes de 2010 (Tabela 1), verifica-se que os dados da estação SDOM4300 são adequados para comparar as alterações causadas pela zona urbana de Catanduva sobre o RSD em relação aos do ponto SDOM4500 antes e depois da ETE.

Os métodos de coleta e análise das amostras foram realizados de acordo com as normas vigentes. As amostras de 2010 e 2011 foram coletadas conforme CETESB (1988) e, nos demais anos, de acordo com o Guia Nacional de Coleta e Preservação de Amostras da CETESB (2011a). Foram consideradas 48 coletas realizadas bimestralmente pela CETESB na estação SDOM4300 e outras 48 na estação SDOM4500 no período de 2010 a 2017. Os parâmetros considerados neste trabalho foram: $\mathrm{pH}$, temperatura, turbidez, sólidos totais (ST), DBO, OD, nitrogênio amoniacal (N-Amon.), fósforo total (Ptotal) e coliformes termotolerantes entre 2010 e 2011/Escherichia coli entre 2012 e 2017. Os métodos de determinações analíticas seguiram, entre 2010 e 2012, os procedimentos estabelecidos no Standard Methods (APHA, 2005) e, entre 2013 e 2017, as diretrizes estabelecidas na nova versão desse documento (APHA, 2012). Os dados não detectados de DBO e Ptotal representaram 16 e 6,25\% do total de amostras, sendo substituídos pelos seus limites de detecção divididos por dois (USEPA, 2000). Todos os demais parâmetros foram detectados em todas as amostragens.

A análise dos dados de qualidade da água do RSD abrangeu sequencialmente a análise de componentes principais (ACP), gráficos de boxplot e testes de hipótese. A ACP foi utilizada para a redução de massa de dados com menor perda possível da informação, permitindo também o agrupamento de dados segundos suas variâncias (HONGYU; SANDANIELO; OLIVEIRA JUNIOR, 2016). A ACP foi realizada por meio do software R, considerando os dados coletados na SDOM4300 e na SDOM4500 agrupados nas seguintes categorias:

- "Mont": dados da SDOM4300;

- "JusPre": dados da SDOM4500 antes da ETE de Catanduva (2010 - maio de 2015);

- "JusPos": dados da SDOM4500 após a ETE de Catanduva (julho de 2015 - 2017)

Os parâmetros de qualidade do RSD com maior influência na variância dos dados apontados pela ACP foram analisados em gráficos do tipo boxplot. As caixas do boxplot são delimitadas abaixo pelo primeiro quartil e acima pelo terceiro quartil, abrangendo $50 \%$ dos dados, e as linhas acima e abaixo das caixas, neste trabalho, indicam os valores máximos e mínimos.

O teste de hipótese foi utilizado para a comparação da média dos dados coletados no RSD no ponto SDOM4500 antes e depois da operação da ETE. Foram realizados testes de hipótese no programa ProUCL 5.1.00, utilizando-se o teste não paramétrico de Wilcoxon-Mann-Whitney por ser adequado para determinar se as médias de dois grupos de dados são significativamente diferentes, com um número mínimo de 10 dados de cada população (USEPA, 2015). O teste foi conduzido ao nível de confiança de 99\%. Foi comparada a média de 33 dados de cada parâmetro coletados na SDOM4500 antes da ETE (2010 - maio de 2015) com a média de 15 dados de cada parâmetro coletados após a operação da ETE (julho de 2015 - 2017). A hipótese nula considerada nos testes foi de que a média dos dados antes da ETE eram maiores que as médias após a ETE para DBO, N-Amon., E. coli e Ptotal, enquanto para o parâmetro OD a hipótese nula foi de que a média dos dados antes da ETE era menor que após a ETE. 


\section{RESULTADOS E DISCUSSÃO}

\section{Avaliação da eficiência da estação de tratamento de efluente de Catanduva}

Os parâmetros de qualidade do efluente bruto gerado por Catanduva (SP) associados à vazão média afluente à ETE, de $31.500 \mathrm{~m}^{3} /$ dia, indicam o potencial poluidor do efluente lançado sem tratamento no RSD. A concentração média de DBO de $332 \mathrm{mg} . \mathrm{L}^{-1}$ está na faixa de valor típica de efluente sanitário, entre 300 e $350 \mathrm{mg} . \mathrm{L}^{-1}$, assim como ausência de OD no efluente bruto (Tabela 2). O N-Amon., com concentração média 33,50 mg.L-1 ${ }^{-1}$ está na faixa indicada para efluentes sanitários de 20 - $35 \mathrm{mg} / \mathrm{L}$, assim como a ausência de nitrato (VON SPERLING, 2005).

$\mathrm{O} \mathrm{pH}$ do efluente bruto próximo da neutralidade com variação de 7,13 - 7,53 (Tabela 2), assim como as concentrações de Ptotal e ST, estão nas faixas características de efluente sanitário, de 6,5 - 7,5, 5 - 20 mg.L $\mathrm{L}^{-1}$ e 370 1,160 mg. $\mathrm{L}^{-1}$, respectivamente (JORDÃO; PESSÔA, 2014). Por outro lado, a concentração de $4,6 \times 10^{-3}$ UFC. $100 \mathrm{~mL}^{-1}$ de coliformes termotolerantes foi três ordens de grandeza inferior ao valor mínimo da faixa de $10^{-6}-10^{-9}$ UFC.100 $\mathrm{mL}^{-1}$ (VON SPERLING, 2005).

O efluente tratado da ETE Catanduva sugere que a concepção é adequada ao tratamento do efluente da cidade. A eficiência média de remoção de DBO, de $93,71 \%$, está no intervalo de remoção de 90 - 95\% para lagoas aeradas de mistura completa seguidas de lagoas de sedimentação (JORDÃO; PESSÔA, 2014). A maior concentração de DBO detectada no efluente tratado da ETE Catanduva (23 mg.L $\left.\mathrm{L}^{-1}\right)$ é inferior à concentração de $30 \mathrm{mg} . \mathrm{L}^{-1}$ para lagoas aeradas seguidas de lagoas de sedimentação (USEPA, 2002), bem como inferior ao limite de 120 mg.L L $^{-1}$ imposto pela Resolução CONAMA no 430/11 (BRASIL, 2011). Portanto, a ETE Catanduva é capaz de tratar adequadamente a matéria orgânica carbonácea presente no efluente bruto.

A concepção da ETE influenciou diretamente na oxigenação do efluente tratado. A concentração de OD foi superior a $7 \mathrm{mg} / \mathrm{L}$ em todas as amostragens (Tabela 2), demonstrando que a lagoa aerada e a escada hidráulica são eficientes na transferência de oxigênio para o efluente. Dessa forma, a ETE lança efluente tratado com baixa carga de matéria orgânica carbonácea, além de contribuir com o aumento de OD para o RSD.
As concentrações de N-Amon. foram inferiores a $20 \mathrm{mg} / \mathrm{L}$, atendendo à Resolução CONAMA 430/11. O processo de nitrificação parece ter sido o responsável pela remoção de $\mathrm{N}$-Amon., visto que o nitrato antes não detectado no efluente bruto passou a apresentar concentração de até $7,4 \mathrm{mg} / \mathrm{L}$ no efluente tratado (Tabela 2). As concentrações de nitrato podem ser tóxicas ao ser humano, causando a doença do "sangue azul", entretanto há pesquisas que desmistificam os males causados por esse íon, surgindo até mesmo citações sobre importantes funções do nitrato no organismo humano, principalmente com funções de defesa contra patógenos (LUZ et al., 2008). Entretanto, a disponibilidade de nitrogênio juntamente com fósforo pode causar a eutrofização do curso d'água receptor.

A remoção média de Ptotal pela ETE de Catanduva foi de 25\%, a qual está na faixa prevista de 15 - 25\% para lagoas aeradas/lagoas de sedimentação (USEPA, 2002). Essa remoção limitada pode ser atribuída à inexistência de uma etapa anaeróbia seguida de uma fase aeróbia na ETE de Catanduva, as quais são essenciais para a remoção biológica de fósforo (USEPA, 2010). A baixa remoção de fósforo pela ETE de Catanduva, associada às concentrações de N-Amon. e nitrato (Tabela 2), pode contribuir para a eutrofização do RSD, e o comportamento desses parâmetros devem ser avaliados no curso d'água receptor.

A eficiência de remoção de coliformes termotolerantes na ETE de Catanduva não chegou a 1 unidade log. Esse valor é inferior à redução de $1-2$ unidades log prevista na literatura para lagoas aeradas/lagoas de sedimentação (VON SPERLING, 2005), porém a eficiência de remoção de $69,57 \%$ está na faixa prevista de 60 - 90\% para essa concepção de tratamento (JORDÃO; PESSÔA, 2014).

$\mathrm{O}$ efluente tratado apresentou $\mathrm{pH}$ próximo da neutralidade. A turbidez do efluente tratado apresentou valor máximo de $36 \mathrm{UNT}$, o qual é inferior à concentração indicada de 40 UNT em rios de água doce Classe 1 (BRASIL, 2005). No que tange aos ST, a ETE de Catanduva apresentou remoção média de $32 \%$, muito próxima da remoção de $29 \%$ da ETE Pirajá, composta de lagoa facultativa aerada seguida de lagoa de maturação (MARÇAL; SILVA, 2017). Diante das reduções de carga orgânica, de turbidez, de ST, da baixa remoção de fósforo e das alterações na forma do nitrogênio presente no efluente tratado, é necessário verificar quais os impactos da operação da ETE Catanduva na qualidade da água do RSD.

Tabela 2 - Características do efluente bruto e tratado da ETE Catanduva.

\begin{tabular}{|c|c|c|c|c|c|c|c|}
\hline \multirow{2}{*}{ Parâmetros } & \multicolumn{3}{|c|}{ Efluente bruto } & \multicolumn{3}{|c|}{ Efluente tratado } & \multirow{2}{*}{ Eficiência média (\%) } \\
\hline & Mín. & Média & Máx. & Mín. & Média & Máx. & \\
\hline $\mathrm{pH}$ & 7,13 & $7,34 \pm 0,12$ & 7,36 & 7,26 & $7,38 \pm 0,07$ & 7,48 & - \\
\hline Temperatura $\left({ }^{\circ} \mathrm{C}\right)$ & 21,1 & $22,83 \pm 0,79$ & 23,9 & 22,9 & $23,87 \pm 1,69$ & 26,7 & - \\
\hline Turbidez (UNT) & 178 & $190,57 \pm 16$ & 229 & 26 & $28,30 \pm 3,23$ & 36 & $85,16 \pm 0,99$ \\
\hline Sólidos Totais & 585 & $726 \pm 56,43$ & 764 & 467 & $490,43 \pm 18,19$ & 520 & $31,75 \pm 8,18$ \\
\hline OD & \multicolumn{3}{|c|}{ Não detectado } & 7,08 & $7,26 \pm 0,17$ & 7,36 & - \\
\hline DBO & 321 & $332,29 \pm 11,38$ & 359 & 20 & $20,86 \pm 1,16$ & 22 & $93,71 \pm 0,45$ \\
\hline N-Amon. & 27,8 & $33,50 \pm 4,07$ & 40,4 & 6,2 & $8,63 \pm 3,98$ & 17,6 & $73,12 \pm 16,19$ \\
\hline Nitrato & $<0,3$ & & & 2,9 & $4,7 \pm 1,72$ & 7,4 & - \\
\hline Ptotal & 3,52 & $4,91 \pm 0,61$ & 5,71 & 3,36 & $3,59 \pm 0,54$ & 3,82 & $25,7 \pm 13,20$ \\
\hline Coliformes termotolerantes* & $4,6 \mathrm{E}+\mathrm{O} 3$ & & & $1,4 \mathrm{E}+\mathrm{O} 3$ & & & 69,57 \\
\hline
\end{tabular}

Mín: mínimo; máx: máximo UNT: unidade nefelométrica de turbidez; OD: oxigênio dissolvido; DBO: demanda bioquímica de oxigênio; N-Amon.: nitrogênio amoniacal;

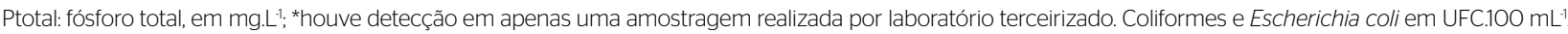
Fonte: adaptada de SAEC (2017) 


\section{Qualidade da água do rio São Domingos}

Os dados de qualidade da água do RSD a montante e a jusante da cidade de Catanduva foram submetidos a ACP. Os eixos 1 e 2 da ACP explicaram juntos $64,3 \%$ da variância total dos dados de qualidade da água do RSD (Figura 2), portanto esses eixos resumem de forma efetiva a variância amostral e podem ser utilizados para o estudo de conjunto de dados (HONGYU; SANDANIELO; OLIVEIRA JUNIOR, 2016). O Eixo 1 (PC1) foi capaz de distinguir as três categorias de dados ("Mont", "JusPre" e "JusPos") em função dos parâmetros N-Amon., DBO, E. coli, Ptotal e OD. As amostras a montante da zona urbana de Catanduva indicam que o RSD apresenta elevadas concentrações de OD e baixa concentração de N. Amon., DBO, E. coli e Ptotal, demonstrando o baixo grau de poluição desse curso d'água (Figura 2). O lançamento de efluente sanitário sem tratamento pela zona urbana de Catanduva causou a degradação da qualidade do RSD, resultando em baixa concentração de OD e aumento da matéria orgânica nitrogenada e carbonácea, além de aumento de E. coli e Ptotal no curso d'água (Figura 2 - Jusante "Pré-ETE"). Por outro lado, o início da operação da ETE indicou a recuperação do RSD sugerida pela aproximação dos dados coletados a jusante ("Jusante Pós-ETE") daqueles coletados a montante ("Montante"), indicando que o lançamento de efluente tratado provocou menor variância dos parâmetros de qualidade do RSD.

A DBO é um dos parâmetros mais utilizados para a medição da poluição em corpos d'água. A montante da cidade de Catanduva, a DBO no RSD foi inferior a $10 \mathrm{mg} / \mathrm{L}$ em todas as coletas (Figura $3 \mathrm{~A}$ ), enquanto a jusante as concentrações chegaram a atingir 39 mg.L.-1 entre 2010 e 2013 (Figura 3B). As maiores concentrações detectadas em 2014 e 2015 provavelmente foram causadas pelas obras de construção do Lago do Parque dos Ipês em 2014 e, em 2015, pela dragagem em um trecho de 2,4 km no RSD na zona urbana de Catanduva (SÃO PAULO, 2015). A atividade de dragagem permite a ressuspensão da matéria orgânica sedimentada (VON SPERLING, 2007), aumentando a DBO e reduzindo a concentração de OD no período pós-dragagem, conforme verificado por Ferreira, Beretta e Mafalda Júnior (2012) no Porto de Aratu, Baía de Todos os Santos (BA). Os dados de DBO indicavam o elevado grau de degradação da qualidade do RSD pelo lançamento de efluente sanitário bruto da cidade de Catanduva entre 2010 e 2015, visto que esse município lançava, até julho de 2015, 6,433 kg DBO.dia ${ }^{-1}$ no referido curso d’água (CETESB, 2016).

Os dados de DBO coletados após o início da operação da ETE de Catanduva indicam um comportamento diferente do RSD. As concentrações de DBO a jusante nos anos de 2016 e 2017 atingiram os menores valores de todo o período monitorado (Figura 3B). As concentrações de DBO superiores a $10 \mathrm{mg} / \mathrm{L}$ antes da operação da ETE, equivalentes à qualidade péssima do curso d'água, foram reduzidas após a operação da ETE a valores entre 2 e $6 \mathrm{mg} / \mathrm{L}$, correspondendo a um rio relativamente limpo (JORDÃO; PESSÔA, 2014). A média de DBO no RSD após a operação da ETE $(5,73 \mathrm{mg} / \mathrm{L})$ foi significativamente menor que antes da operação da ETE (20,97 mg/L), com nível de confiança de 99\% (Tabela 3). Essa significativa redução de matéria orgânica carbonácea no RSD pode ser atribuída à eficiência de remoção de DBO da ETE Catanduva (Tabela 2).

O OD é o parâmetro de melhor caracterização de um curso dágua (JORDÃO; PESSOA, 2014), pois o oxigênio é o receptor de elétron inicialmente utilizado

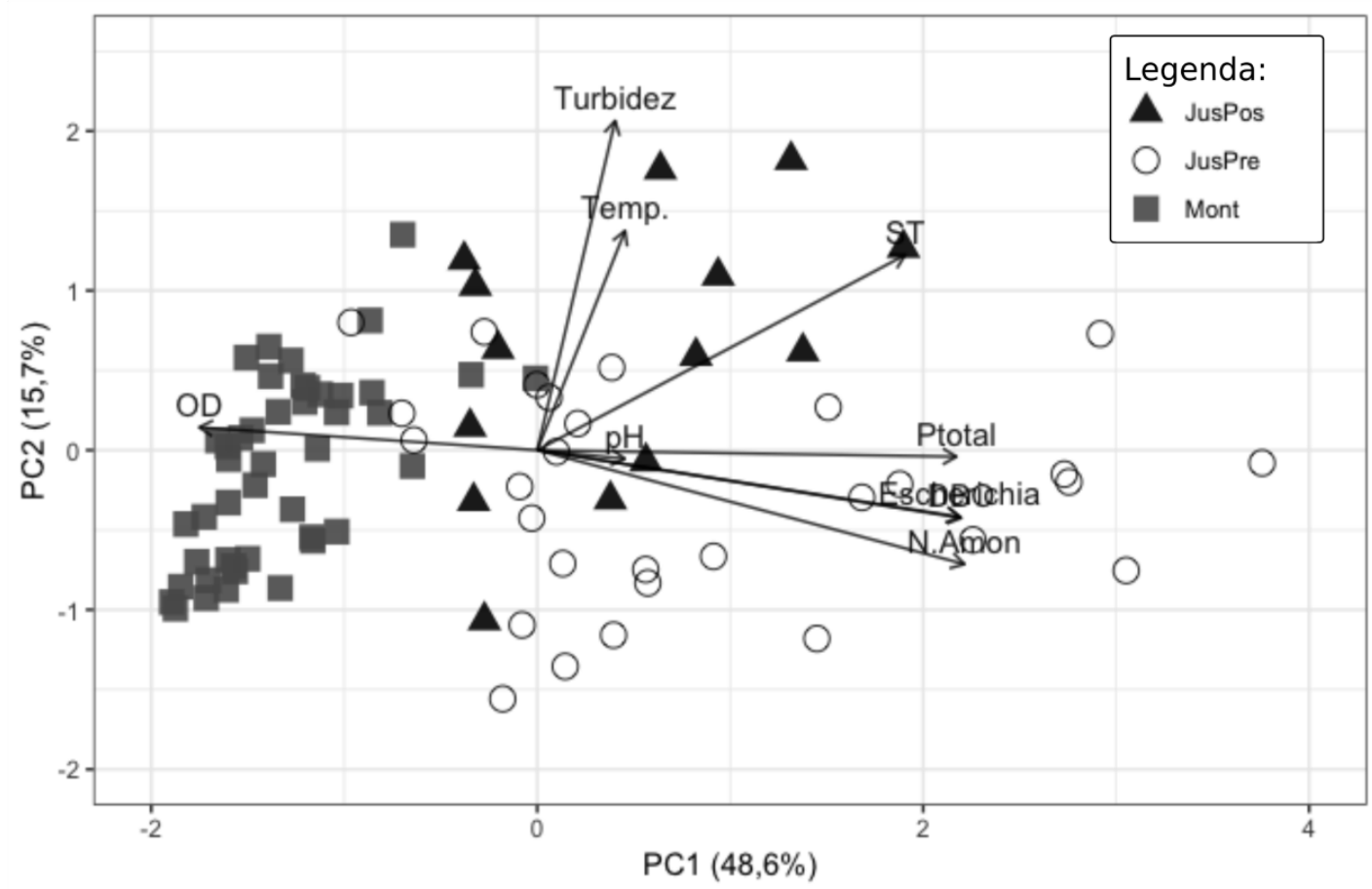

OD: oxigênio dissolvido; Ptotal: fósforo total; N.Amon: nitrogênio amoniacal. Fonte: elaborada pelos autores (2018)

Figura 2 - Diagrama de Análise de Componentes Principais dos parâmetros de qualidade da água do Rio São Domingos. Os autovalores foram agrupados graficamente em três categorias: montante (“Mont"), jusante pré- Estação de Tratamento de Efluente (“JusPre”) e jusante pós-Estação de Tratamento de Efluente (“JusPos”). 
pelos microrganismos para a decomposição da matéria orgânica, já que eles conseguem obter maior energia livre por meio das reações aeróbias (SNOEYINK; JENKINS, 1980). A montante da zona urbana de Catanduva, as concentrações de OD variaram entre 3 e $7 \mathrm{mg} / \mathrm{L}$, enquanto a jusante foram inferiores a 2,5 mg/L entre 2010 e 2014 (Figura 3C), e em 26 das 33 amostras coletadas esse parâmetro esteve abaixo de $1 \mathrm{mg} . \mathrm{L}^{-1}$. No ano de 2014 , a ressuspensão de matéria
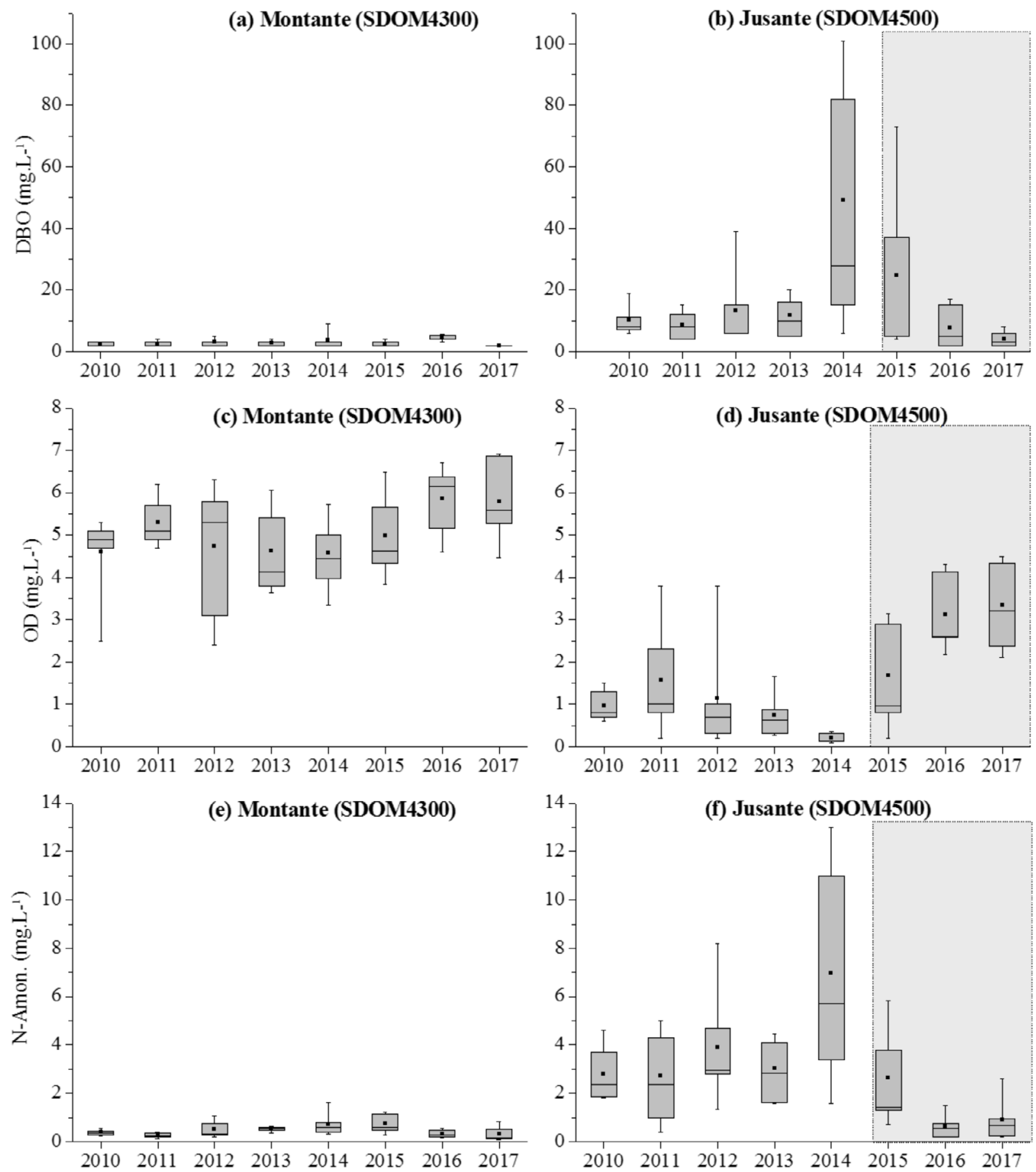

DBO: demanda bioquímica de oxigênio; OD: oxigênio dissolvido; N-Amon.: nitrogênio amoniacal. Fonte: elaborada pelos autores (2018).

Figura 3 - (A e B) Concentrações de demanda bioquímica de oxigênio, (C e D) oxigênio dissolvido e (E e F) nitrogênio amoniacal a montante e a jusante da cidade de Catanduva entre 2010 e 2017. Os retângulos cinzas representam o período de operação da estação de tratamento de efluente. As linhas dos boxplots ( $T$ ) indicam os valores máximos e mínimos, enquanto os quadrados (•) representam a mediana dos dados. 
orgânica por obras de dragagem no Lago dos Ipês culminou em concentrações praticamente nulas de $\mathrm{OD}\left(0,1-0,4 \mathrm{mg} \cdot \mathrm{L}^{-1}\right)$, coincidindo com as maiores concentrações de DBO, N-Amon., Ptotal, E. coli e ST. O lançamento de efluente bruto pela zona urbana de Catanduva causava concentrações de OD inferiores a $2 \mathrm{mg} . \mathrm{L}^{-1}$ (Figura 3D), desrespeitando também a concentração pretendida de $2 \mathrm{mg} / \mathrm{L}$ para rios Classe 4 da Resolução CONAMA n 357/05 (BRASIL, 2005). Um dos efeitos das baixas concentrações de OD e da ausência de nitrato no curso d'água (Figura 4) é a geração de odor, pela conversão do sulfato em bissulfeto (SNOEYINK; JENKINS, 1980). Essa condição provavelmente era responsável pela emissão de odores pelo RSD, o que gerava muitas queixas dos moradores de Catanduva e Catiguá (SP). Dessa forma, o efluente doméstico lançado por
Catanduva consumia praticamente todo o OD no rio, causando desconforto olfativo aos moradores das duas cidades.

A operação da ETE de Catanduva aumentou a concentração de OD no RSD. Após o início da operação, em 2015, as concentrações de OD no RSD, em 2016 e 2017, foram as maiores entre todo o período considerado (Figura 3D). A média de OD no RSD após o início da operação da ETE $(3,12 \mathrm{mg} / \mathrm{L})$ foi significativamente maior que antes dele $(0,90 \mathrm{mg} / \mathrm{L})$, com nível de confiança de $99 \%$ (Tabela 3), superando a concentração mínima de OD prevista $\left(2 \mathrm{mg} \cdot \mathrm{L}^{-1}\right)$ pela Resolução CONAMA no 357/05 para rios Classe 4 (BRASIL, 2005). Esse aumento na concentração de OD no RSD pode ser atribuído ao efluente tratado, com baixa concentração de DBO (19 - 23 mg.L-1 $)$ e de N-Amon. (4,5 - 17,5 mg.L-1 $)$ e elevada

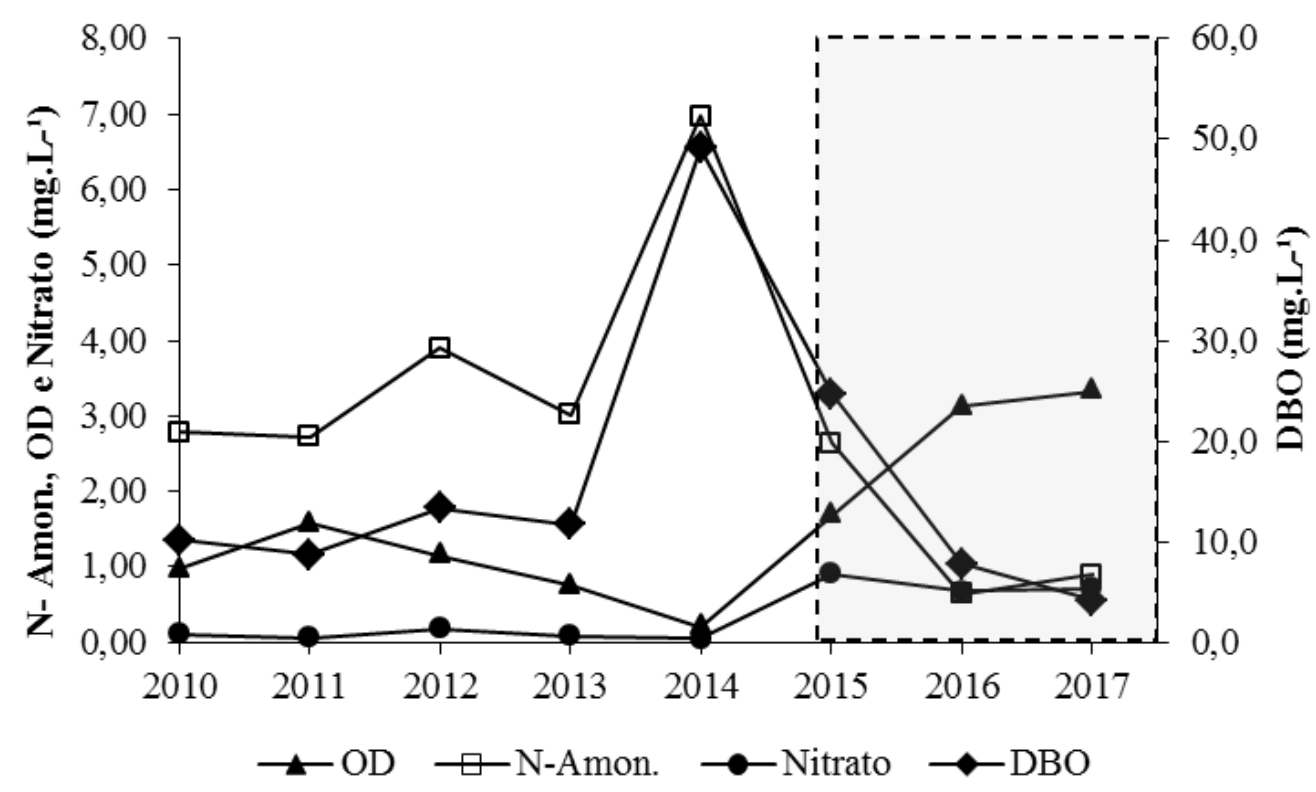

N-Amon.: nitrogênio amoniacal; OD: oxigênio dissolvido; DBO: demanda bioquímica de oxigênio.

Fonte: Elaborada pelos autores (2018).

Figura 4 - Médias das concentrações de oxigênio dissolvido, nitrogênio amoniacal, nitrato e demanda bioquímica de oxigênio antes da operação da Estação de Tratamento de Efluente (2010-2014) e após o início da operação (2015-2017). O retângulo cinza representa o período de operação da estação de tratamento de efluente.

Tabela 3 - Médias, desvios padrão e testes estatísticos das médias dos parâmetros do rio São 486 Domingos pré-Estação de Tratamento de Efluente (SDOM4500 Pré-ETE) e pós-Estação de Tratamento de Efluente (SDOM4500 Pós-ETE).

\begin{tabular}{|c|c|c|c|c|}
\hline Parâmetro & SDOM 4500 Pré-ETE & SDOM4500 Pós-ETE & $\begin{array}{l}\text { Nivel de Confiança (Teste } \\
\text { Wilcoxon-Mann-Whitney) }\end{array}$ & Rio São Domingos após a ETE \\
\hline Sólidos Totais & $202,9 \pm 80,62$ & $242,9 \pm 58,68$ & \multirow{6}{*}{$99 \%$} & Não houve alteração \\
\hline OD & $0,90 \pm 0,90$ & $3,12 \pm 0,85$ & & Houve aumento \\
\hline DBO & $20,97 \pm 24,30$ & $5,73 \pm 4,54$ & & Houve redução \\
\hline N-Amon. & $3,84 \pm 2,72$ & $0,99 \pm 0,82$ & & Houve redução \\
\hline Ptotal & $0,51 \pm 0,48$ & $0,69 \pm 0,37$ & & Não houve alteração \\
\hline Coliformes/Escherichia coli & $8,02 E+05 \pm 1,22 E+06$ & $\begin{array}{l}5,76 \mathrm{E}+04 \\
\pm 1,24 \mathrm{E}+05\end{array}$ & & Houve redução \\
\hline
\end{tabular}

OD: oxigênio dissolvido; DBO: demanda bioquímica de oxigênio; N-Amon.: nitrogênio amoniacal; Ptotal: fósforo total; ETE: estação de tratamento de esgoto. Fonte: elaborada pelos autores (2018). 
concentração de OD (> 7 mg.L-1 $)$, em razão da lagoa aerada e da ação da escada hidráulica antes do lançamento do efluente tratado (Tabela 2). Com a redução na demanda de oxigênio para a estabilização da matéria orgânica carbonácea e nitrogenada, associada à elevada concentração de OD no efluente tratado, houve aumento de OD no RSD.

O parâmetro N-Amon. também deve ser analisado no lançamento de esgoto sanitário, visto que sua conversão a nitrato (nitrificação) também consome OD do curso d'água. Essa demanda de oxigênio é chamada DBO nitrogenada, e, em cursos d'água receptores, a DBO carbonácea é oxidada primeiramente, seguida pela DBO nitrogenada (TCHOBANOGLOUS; BURTON; STENSEL, 1991). Isso indica a importância da análise da conversão de N-Amon. a nitrato na avaliação do impacto do lançamento de efluentes. As concentrações de N-Amon. no RSD a montante da cidade de Catanduva variaram, no período analisado, de 0,26 a $0,73 \mathrm{mg} \cdot \mathrm{L}^{-1}$ (Figura $3 \mathrm{E}$ ), indicando que o RSD não recebia lançamento significativo de efluente sanitário a montante. Por outro lado, a jusante de Catanduva esse parâmetro atingiu concentrações que variaram de 0,4 a 8,2 mg. $\mathrm{L}^{-1}$ entre 2010 e 2013 e, em virtude de obras de dragagem para a implantação do Lago dos Ipês, atingiu a concentração máxima de $13 \mathrm{mg} \cdot \mathrm{L}^{-1}$ no rio em 2014 (Figura 3F). As elevações nas concentrações de N-Amon. no RSD a jusante da zona urbana de Catanduva confirmam o impacto do lançamento de efluente sem tratamento nesse curso d'água. Por outro lado, devem ser analisadas possíveis alterações na concentração de nitrato no RSD, tendo em vista que esse é o produto final da oxidação do N-Amon., e a ETE de Catanduva não possui a etapa de desnitrificação.

As concentrações de N-Amon. foram alteradas significativamente após o início da operação da ETE de Catanduva. Nos anos de 2016 e 2017 esses níveis foram os menores registrados em todo o período considerado (Figura $3 \mathrm{~F}$ ). A média desse parâmetro no RSD após o início da operação da ETE $(0,99 \mathrm{mg} / \mathrm{L})$ foi significativamente menor que antes dele $(3,84 \mathrm{mg} / \mathrm{L})$, com nível de confiança de $99 \%$ (Tabela 3). As concentrações desse parâmetro no rio com a operação da ETE são muito próximas daquelas encontradas a montante de Catanduva, portanto a carga de N-Amon. lançada pela ETE parece ser compatível com a capacidade de autodepuração do corpo receptor. Isso porque praticamente não houve aumento desse parâmetro a jusante da cidade em relação a montante, e a DBO nitrogenada remanescente do efluente tratado não foi suficiente para baixar os níveis de OD.

O município de Catanduva interferiu na forma em que o nitrogênio esteve disponível no RSD. Antes da operação da ETE, praticamente não havia nitrato no RSD a jusante de Catanduva (Figura 4) e, após o seu início, as concentrações médias desse íon chegaram a atingir $0,9 \mathrm{mg} / \mathrm{L}$ (2015 - 2017). Esse aumento no curso d'água pode ser explicado pelo lançamento de efluente tratado com concentração de nitrato média de $4,7 \mathrm{mg} . \mathrm{L-}^{1}$ (Tabela 2), bem como pela preferência dos microrganismos presentes no rio por utilizar o OD como receptor de elétron antes da utilização do nitrato (SNOEYINK; JENKINS, 1980), diminuindo o consumo desse íon. O lançamento de efluente contendo nitrogênio pode contribuir para o processo de eutrofização do curso d'água, sendo necessário analisar conjuntamente os teores de Ptotal presentes nele.

O fósforo é o nutriente limitante para a ocorrência de eutrofização de cursos d'água (AISSA-GROUZ; GARNIER; BILLEN, 2018). As concentrações de Ptotal a montante da cidade de Catanduva estiveram abaixo de $0,25 \mathrm{mg} \cdot \mathrm{L}^{-1}$, enquanto a zona urbana de Catanduva contribuiu para o aumento na concentração desse nutriente em todo o período monitorado (Figura 5). Após o início da operação da ETE, não houve redução significativa das concentrações de Ptotal no curso d'água, visto que a estação não possui tratamento terciário e a remoção de Ptotal é limitada (Tabela 2). A instalação de tratamento terciário demanda um investimento elevado, podendo ser avaliada a possibilidade de utilização do efluente tratado na irrigação de culturas ou até na umectação de vias não pavimentadas - desde que observadas as questões de emissão de odores e de transmissão de doenças de veiculação hídrica, já que a ETE Catanduva não possui etapa de desinfecção.

As bactérias do grupo $E$. coli são utilizadas como organismos indicadores de contaminação fecal (humana e animal), e sua presença indica elevada probabilidade da existência de patógenos (USEPA, 2001). As concentrações de E. coli a montante da cidade de Catanduva estiveram na ordem de $10^{3}$ e $10^{4}$ UFC. $100 \mathrm{~mL}^{-1}$ (Figura 5C), enquanto a jusante da zona urbana da cidade aumentaram em até duas ordens de grandeza (Figura 5D). Com a operação da ETE, essas concentrações no RSD permaneceram na ordem de $10^{3}$ a $10^{5} \mathrm{UFC} / 100 \mathrm{~mL}$ (Figura 5), mas atingiram as menores concentrações de todo o período monitorado no ano de 2017. Mesmo não havendo etapa de desinfecção do efluente na ETE, a média de E. coli no RSD após o início da operação da ETE $\left(5,76 \times 10^{4} \mathrm{UFC} 100 \mathrm{~mL}^{-1}\right)$ foi significativamente menor que antes dele $\left(8,02 \times 10^{5}\right.$ UFC.100 mL- $\left.{ }^{1}\right)$, com nível de confiança de $99 \%$ (Tabela 3).

A presença de sólidos nos cursos d'água ocorre naturalmente, mas em concentrações elevadas interferem no tratamento de água e nos recursos pesqueiros, podendo causar sérios danos ecológicos (BILOTTA; BRAZIER, 2008). Os ST a montante de Catanduva apresentaram a maior parte das concentrações entre 100 e $250 \mathrm{mg} / \mathrm{L}$. Após a passagem pela zona urbana catanduvense, houve aumento na concentração desse parâmetro em todos os anos.

Essa contribuição do processo de urbanização para a entrada de sólidos em cursos dágua também foi observada por Cunha, Bottino e Calijuri (2010) na bacia do Ribeira do Iguape, no Estado de São Paulo. No caso do RSD, as maiores concentrações de ST observadas nos anos de 2014 e 2015 decorreram de atividades de dragagem no RSD, o que também resultou no aumento de DBO, N-Amon. (Figura 3) e Ptotal (Figura 5), acompanhado do decréscimo de OD (Figura 3). A operação da ETE de Catanduva não permitiu redução de significativa na concentração de ST no RSD (Tabela 3), visto que esse parâmetro também é influenciado pelo uso e ocupação do solo da bacia.

A ETE de Catanduva, em menos de dois anos de operação, já trouxe significativa melhoria na qualidade do RSD, com redução de matéria orgânica carbonácea, nitrogenada e E. coli, além de ser responsável pelo aumento da concentração de OD. A tendência de recuperação desse curso d'água vem-se confirmando pelos seus índices de qualidade da água, que evoluiu no ponto SDOM4500 de "péssima" em 2014 para "regular" em 2017 (CETESB, 2018). Se a ETE Catanduva for operada adequadamente, se houver fiscalização contínua das ligações prediais e, futuramente, a etapa de remoção de nutrientes for implantada, espera-se melhora contínua na qualidade da água do RSD. No entanto, é importante que sejam adotadas também boas práticas agrícolas na bacia hidrográfica, pois mesmo após o atendimento de todas as metas de tratamento do efluente sanitário urbano ainda poderão ser encontrados valores elevados de nutrientes que podem promover a eutrofização, como observado em m estudo realizado na França (GARNIER et al., 2018). 


\section{CONCLUSÕES}

A ETE de Catanduva é eficiente na remoção de matéria orgânica carbonácea e nitrogenada, além de lançar efluente tratado no RSD com elevadas concentrações de OD. Entretanto, a remoção de Ptotal e E. coli é limitada pela inexistência de etapa de remoção de nutriente e desinfecção na ETE. Ainda assim, o efluente tratado atende à legislação estadual e federal.

A qualidade da água do RSD apresentou significativa melhoria após o início da operação da ETE Catanduva. A ACP indicou que os dados
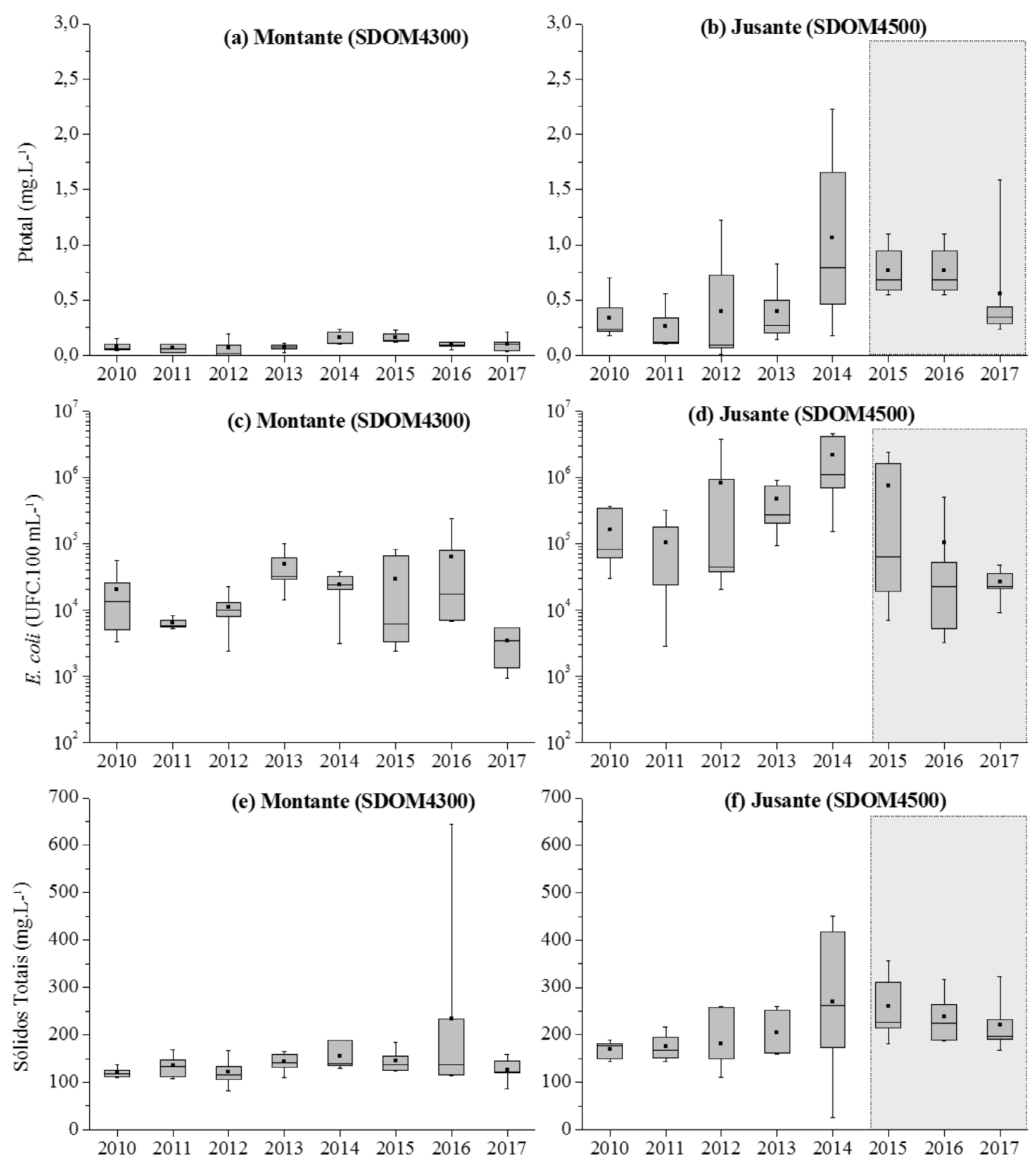

Ptotal: fósforo total.

Fonte: elaborada pelos autores (2018).

Figura 5 - (A e B) Concentrações de fósforo total, (C e D) E. coli e (E e F) sólidos totais a montante e a jusante da cidade de Catanduva. Os retângulos cinzas representam o período de operação da estação de tratamento de efluente. As linhas dos boxplots $(\top)$ indicam os valores máximos e mínimos, enquanto os quadrados (•) representam a mediana dos dados. 
coletados a jusante da cidade após a implantação da ETE se aproximaram dos coletados a montante da zona urbana catanduvense, indicando que o efluente tratado causa menor variação de qualidade do rio em relação a montante, portanto é compatível com a capacidade de autodepuração do RSD.

A utilização da água do RSD poderá ser ampliada futuramente. Os usos pretendidos atualmente são restritos à harmonia paisagística e à navegação, pelo fato de o RSD ser classificado como Classe 4, conforme Resolução CONAMA $n^{\circ}$ 357/05 (BRASIL, 2005). A ETE de Catanduva trouxe significativa melhoria ao RSD, evidenciada pelos parâmetros que passaram atender aos limites de rios Classe 3. Portanto, há a possibilidade de que futuramente o RSD possa ser utilizado para abastecimento humano após o devido tratamento da água, além de para a irrigação de culturas arbóreas, recreação secundária e dessedentação animal. A pesca amadora voltou a ocorrer na zona urbana de Catanduva, até mesmo com eventos promovidos pelo poder público, como o denominado de Pesque \& Preserve.

\section{AGRADECIMENTOS}

Aos servidores da Superintendência de Água e Esgoto de Catanduva (SAEC) Sr. Marcus Augusto Jardim e Sr. Renato Centurion Stuchi a colaboração com informações essenciais ao presente estudo.

\section{CONTRIBUIÇÕES DOS AUTORES}

Fonseca, W. C.: Conceituação, Análise Formal, Investigação, Metodologia, Escrita - Primeira Redação, Escrita - Revisão e Edição. Tibiriçá, C. E. J. A.: Software, Escrita - Revisão e Edição.

\section{REFERÊNCIAS}

AISSA-GROUZ, N.; GARNIER, J.; BILLEN, G. Long trend reduction of phosphorus wastewater loadingin the Seine: determination of phosphorus speciation and sorption for modeling algal growth. Environmental Science and Pollution Research, v. 25, p. 23515-23528, 2018. https://doi.org/10.1007/ s11356-016-7555-7

AMERICAN PUBLIC HEALTH ASSOCIATION (APHA). Standard Methods for the Examination Water and Wastewater. 21a ed. Washington, D.C.: American Public Health Association, 2005

AMERICAN PUBLIC HEALTH ASSOCIATION (APHA). Standard Methods for the Examination Water and Wastewater. 22a ed. Washington, D.C.: American Public Health Association, 2012.

BARILE, P.J. Widespread sewage pollution of the Indian River Lagoon system, Florida (USA) resolved by spatial analyses of macroalgal biogeochemistry. Marine Pollution Bulletin, v. 128, p. 557-574, 2018. https:// doi.org/10.1016/..marpolbul.2018.01.046

BILOTTA, G.S.; BRAZIER, R.E. Understanding the influence of suspended solids water quality and aquatic biota. Water Research, v. 42, n. 12, p. 28492861, 2008. https://doi.org/10.1016/j.watres.2008.03.018

BRASIL. Conselho Nacional do Meio Ambiente (CONAMA). Resolução no 357, de 17 de março de 2005. Dispõe sobre a classificação dos corpos d’água e diretrizes ambientais para o seu enquadramento, bem como estabelece as condições e padrões de lançamento de efluentes, e dá outras providências. Diário Oficial da União, Brasília, 18 mar. 2005. Disponível em: http://www2.mma.gov.br/port/conama/legiabre.cfm?codlegi=459. Acesso em: 19 set. 2018.

BRASIL. Conselho Nacional do Meio Ambiente (CONAMA). Resolução no 430, de 13 de maio de 2011. Dispõe sobre as condições e padrões de lançamento de efluentes, complementa e altera a Resolução no 357, de 17 de março de 2005, do Conselho Nacional do Meio AmbienteCONAMA. Diário Oficial da União, Brasília, 16 maio 2011. Disponível em: http://www2.mma.gov.br/port/conama/legiabre.cfm?codlegi=646. Acesso em: 19 set. 2018.
BRASIL. Ministério das Cidades. Secretaria Nacional de Saneamento Ambiental (SNSA). Sistema Nacional de Informações sobre Saneamento. Diagnóstico dos Serviços de Água e Esgotos - 2015. Brasília: SNSA/ MCIDADES, 2017. $212 \mathrm{p}$.

COMITE DA BACIA HIDROGRÁFICA DO TURVO/GRANDE (CBH-TG) Relatório de Situação dos Recursos Hidricos 2017 - UGRHI 15 - Turvo / Grande. CBH-TG, 2018. Disponível em: http://www.sigrh.sp.gov.br/ relatoriosituacaodosrecursoshidricos. Acesso em: 20 fev. 2018.

COMPANHIA AMBIENTAL DO ESTADO DE SÃO PAULO (CETESB). Guia de Coleta e Preservação de Amostras de Água. São Paulo: Cetesb, 1988.

COMPANHIA AMBIENTAL DO ESTADO DE SÃO PAULO (CETESB). Guia nacional de coleta e preservação de amostras: água, sedimento, comunidades aquáticas e efluentes líquidos. São Paulo: Cetesb, Brasília: ANA, 2011a. 326 p.

COMPANHIA AMBIENTAL DO ESTADO DE SÃO PAULO (CETESB). Qualidade das águas superficiais no estado de São Paulo 2010. São Paulo: Cetesb, 2011b. 298 p. Série Relatórios. Disponível em: http://cetesb.sp.gov.br/ aguas-interiores/publicacoes-e-relatorios/. Acesso em: 22 fev. 2018.

COMPANHIA AMBIENTAL DO ESTADO DE SÃO PAULO (CETESB). Qualidade das águas superficiais no estado de São Paulo 2011. São Paulo: Cetesb, 2012. 356 p. Série Relatórios. Disponível em: https://cetesb.sp.gov.br/ aguas-interiores/publicacoes-e-relatorios/. Acesso em: 22 fev. 2018.

COMPANHIA AMBIENTAL DO ESTADO DE SÃO PAULO (CETESB). Qualidade das águas superficiais no estado de São Paulo 2012. São Paulo: Cetesb, 2013. 370 p. Série Relatórios. Disponível em: https://cetesb.sp.gov.br/ aguas-interiores/publicacoes-e-relatorios/. Acesso em: 22 fev. 2018.

COMPANHIA AMBIENTAL DO ESTADO DE SÃO PAULO (CETESB). Qualidade das águas superficiais no estado de São Paulo 2013: Apêndice I. São Paulo: Cetesb, 2014. 434 p. Série Relatórios. Disponível em: https:// cetesb.sp.gov.br/aguas-interiores/publicacoes-e-relatorios/. Acesso em: 22 fev. 2018 
COMPANHIA AMBIENTAL DO ESTADO DE SÃO PAULO (CETESB). Qualidade das águas superficiais no estado de São Paulo 2014: Apêndice I. São Paulo: Cetesb, 2015. 540 p. Série Relatórios. Disponível em: https:// cetesb.sp.gov.br/aguas-interiores/publicacoes-e-relatorios/. Acesso em: 22 fev. 2018.

COMPANHIA AMBIENTAL DO ESTADO DE SÃO PAULO (CETESB). Qualidade das águas superficiais no estado de São Paulo 2016: Apêndice K. São Paulo: Cetesb, 2017. 287 p. Série Relatórios. Disponível em: https:// cetesb.sp.gov.br/aguas-interiores/publicacoes-e-relatorios/. Acesso em: 22 fev. 2018.

COMPANHIA AMBIENTAL DO ESTADO DE SÃO PAULO (CETESB). Relatório de qualidade das águas interiores do estado de São Paulo 2015. São Paulo: Cetesb, 2016. 562 p. Série Relatórios. Disponível em: http://cetesb.sp.gov.br/ aguas-interiores/publicacoes-e-relatorios/. Acesso em: 22 fev. 2018.

COMPANHIA AMBIENTAL DO ESTADO DE SÃO PAULO (CETESB). Relatório de qualidade das águas interiores do estado de São Paulo 2017. São Paulo: Cetesb, 2018. 303 p. Série Relatórios. Disponível em: http://cetesb.sp.gov.br/ aguas-interiores/publicacoes-e-relatorios/. Acesso em: 22 fev. 2018.

CUNHA, D.G.F.; BOTTINO, F.; CALIJURI, M.C. Land use influence on eutrophication-related water variables: case study of tropical rivers with different degrees of anthropogenic interference. Acta Limnologica Brasiliensia, v. 22, n. 1, p. 35-45, 2010. https://doi.org/10.4322/ actalb.02201005

FERREIRA, A.N.; BERETTA, M.; MAFALDA JÚNIOR, P.O. Avaliação do impacto da dragagem sobre associação de fitoplâncton do Porto de Aratu, Baía de Todos os Santos, Bahia. Arquivos de Ciências do Mar, v. 45, n. 1, p. 30-46, 2012

GARNIER, J.; RAMARSON, A.; THIEU, V.; NÉMERY, J.; THÉRY, S.; BILLEN, G.; COYNEL, A. How can water quality be improved when the urban waste water directive has been fulfilled? A case study of the Lot river (France). Environmental Science and Pollution Research, v. 25, p. 11924-11939, 2018. https://doi.org/10.1007/s11356-018-1428-1

HONGYU, K.; SANDANIELO, V.L.M.; OLIVEIRA JUNIOR, G.J. Análise de Componentes Principais: resumo teórico, aplicação e interpretação. Engineering and Science, v. 5, n. 1, p. 83-90, 2016. https://doi.org/10.18607/ ES201653398

INSTITUTO BRASILEIRO DE GEOGRAFIA E ESTATISTICA (IBGE). Catanduva: Estimativa da População de 2017. Disponível em: https://cidades.ibge.gov. brl. Acesso em: 30 jan. 2018

JORDÃO, E.P.; PESSÔA, C.A. Tratamento de Esgotos Domésticos. 7a ed. Rio de Janeiro: Associação Brasileira de Engenharia Sanitária e Ambiental (Abes), 2014. $1050 \mathrm{p}$.

LUZ, G.L.; MEDEIROS, S.L.P.; MANFRON, P.A.; AMARAL, A.D.; MÜLLER, L.; TORRES, M.G.; MENTGES, L. A questão do nitrato em alface hidropônica e a saúde humana. Ciência Rural, v. 38, n. 8, p. 2388-2394, 2008. https://doi. org/10.1590/S0103-84782008000800049

MARÇAL, D.A.; SILVA, C.E. Avaliação do impacto do efluente da estação de tratamento de esgoto ETE-Pirajá sobre o Rio Parnaíba, Teresina (PI). Engenharia Sanitária e Ambiental, v. 22, n. 4, p. 761-772, 2017. https://doi. org/10.1590/s1413-41522017148242
SÃO PAULO (Estado). Decreto no 10.755, de 22 de novembro de 1977. Dispõe sobre o enquadramento dos corpos de água receptores na classificação prevista no Decreto no 8.468, de 8 de setembro de 1976 e dá providências correlatas. Diário Oficial do Estado de São Paulo, São Paulo, 23 nov. 1977. Disponível em: https://www.al.sp.gov.br/norma/153028. Acesso em: 2 maio 2019

SÃO PAULO (Estado). Sistema de Gerenciamento Integrado de Recursos Hídricos de São Paulo. DAEE realiza desassoreamento em rio de Catanduva. São Paulo, 2015. Disponível em: http://www.sigrh.sp.gov.br/pageitems/450/ news/66. Acesso em: 19 set. 2018

SNOEYINK, V.L.; JENKINGS, D. Water Chemistry. Nova York: John Wiley \& Sons, 1980. 464 p.

SUPERINTENDÊNCIA DE ÁGUA E ESGOTO DE CATANDUVA (SAEC) Estação de Tratamento de Esgotos de Catanduva - Relatório Semestral CETESB - Novembro/2016 - Maio/2017. São Paulo: Cetesb, 2017.

TAMBELLINI, C.A. Ações e Projetos Ambientais e a Qualidade das Aguas na Sub-bacia do Rio São Domingos, SP (UGRH-Turvo/Grande), no Período de 2000 a 2010. 82f. Dissertação (Mestrado em Desenvolvimento Regional e Meio Ambiente) - Centro Universitário de Araraquara, Araraquara, 2012. Disponível em: https://m.uniara.com.br/arquivos/file/ppg/desenvolvimentoterritorial-meio-ambiente/producao-intelectual/dissertacoes/2012/cassiaaparecida-tambellini.pdf. Acesso em: 10 mar. 2018.

TCHOBANOGLOUS, G.; BURTON, F.L.; STENSEL, H.D. Wastewater Engineering: treatment, disposal, and reuse. 3 a ed. Nova York: McGraw Hill Book, 1991. 1334 p.

UNITED STATES ENVIRONMENTAL PROTECTION AGENCY (USEPA) Guidance for Data Quality Assessment. EPA/600/R-96/084. Washington, D.C.: USEPA, 2000

UNITED STATES ENVIRONMENTAL PROTECTION AGENCY (USEPA). Office of Research and Development/National Risk Management Research Laboratory. Nutrient Control Design Manual. EPA/600/R-10/100. Cincinatti: USEPA, 2010. Disponível em: https://cfpub.epa.gov/si/si_public_record report.cfm?dirEntryld=227683. Acesso em: 12 out. 2018.

UNITED STATES ENVIRONMENTAL PROTECTION AGENCY (USEPA). Parameters of water quality: Interpretation and Standards. WexfordL USEPA, 2001. Disponível em: https://www.epa.ie/pubs/advice/water/quality/ Water_Quality.pdf. Acesso em: 19 set. 2018.

UNITED STATES ENVIRONMENTAL PROTECTION AGENCY (USEPA) ProUCL Version 5.1 User Guide: Statistical Software for Environmental Applications for Data Sets with and without Nondetect Observations. EPA/600/R-07/O41. Washington, D.C.: USEPA, 2015.

UNITED STATES ENVIRONMENTAL PROTECTION AGENCY (USEPA) Wastewater Technology Fact Sheet: Aerated, Partial Mix Lagoons. EPA 832F-O2-008. Washington, D.C.: USEPA, 2002.

VON SPERLING, M. Estudos e modelagem da qualidade da água de rios. Belo Horizonte: Departamento de Engenharia Sanitária e Ambiental/ Universidade Federal de Minas Gerais, 2007. 588 p.

VON SPERLING, M. Introdução à qualidade das águas e ao tratamento de esgotos. $3^{a}$ ed. Belo Horizonte: Departamento de Engenharia Sanitária e Ambiental/Universidade Federal de Minas Gerais, 2005. 243 p. 